\title{
Microbiology of chronic suppurative otitis media: a prospective study in a tertiary care hospital
}

\begin{abstract}
Objective: Aim of the study is to find out the microbiological profile and their antibiotic sensitivity patterns in patients with chronic suppurative otitis media in a tertiary care hospital.

Materials and methods: A total number of 100 ear swabs were investigated for the present study. Their gram staining, direct microscopy with $\mathrm{KOH}$, culture sensitivity, and biochemical tests were carried out to identify the organisms and to know their sensitivity pattern. All the swabs were collected from patients with clinical diagnosis of chronic suppurative otitis media visiting otolaryngology outpatient department of tertiary care hospital. The study period was One year, from July 2016 to June 2017.

Results: Out of 100 swabs ,fungal culture was positive for 28 (28\% ) swabs , while combined growth of fungi and bacteria obtained from $24(24 \%)$ swabs, only bacteria from $62(62 \%)$ and culture was negative from 10 swabs. Pseudomonas aeruginosa $(37.21 \%)$ was commonly isolated organism followed by Staphylococcus aureus $(27.91 \%)$. Fungal was isolated in 28 cases, out of which $57.14 \%$ were Aspergillus species, followed by Candida $(42.86 \%)$. Amikacin was found to be the most effective antibiotic with low resistance rate.

Conclusion: The study of microbial pattern and their antibiotic sensitivity determines the prevalent organisms causing chronic suppurative otitis media in local area and helps to start appropriate treatment of otitis media and its complications for successful outcome.
\end{abstract}

Volume 9 Issue I - 2017

\author{
Borligegowda Viswanatha, Sreeshma Balan \\ Otorhinolaryngology Department Bangalore Medical College \\ Research Institute, India
}

Correspondence: Borlingegowda Viswanatha Professor of ENT Bangalore Medical College Research Institute Bangalore, India,Tel 919845942832, Email drbviswanatha@yahoo.co.in

Received: October 27, 2017 | Published: November 13, 2017
Abbreviations: CSOM, chronic suppurative otitis media; MRSA, methicillin-resistant s. aureus; CLSI, clinical laboratory standards institute

\section{Introduction}

Chronic suppurative otitis media (CSOM) is a chronic inflammatory process in the middle ear space that results in long term or permanent changes in the tympanic membrane including atelectasis, dimeric membrane formation, perforation, tympanosclerosis, retraction pocket or cholesteatoma. ${ }^{1}$ It is an important health problem in our society.

Inadequate and inappropriate treatment of CSOM can result in a wide range of complications. These may be due to the spread of organisms to structures adjacent to the ear or to local damage in the middle ear itself. Such complications range from persistent otorrhoea, mastoiditis, labyrinthitis, facial nerve paralysis to more serious intracranial abscesses or thromboses. ${ }^{2-4}$

It is a well-known fact that microbial drug resistance is a growing global problem. Among Gram-negative bacteria, the most resistant pathogens are E. coli, Klebsiella species and Psudomonas aeruginosa, with increasing trends observed for all major anti-Gram negative agents (beta-lactams, fluorquinolones and aminoglycosides). ${ }^{5}$ Serious infections caused by Gram-positive bacteria are increasingly difficult to treat because of pathogens such as methicillin-resistant S. aureus (MRSA), and penicillin-resistant S. pneumonia. ${ }^{6}$ The detection of multidrug resistant isolates may further limit therapeutic options. Therefore, the microbial culture and sensitivity will help in appropriate management of otitis media and its complications and thus preventing the emergence of resistant bacterial strain. There is a need to understand the epidemiology and microbiology of CSOM in order to develop effective strategies for primary prevention and better management of the disease. ${ }^{7}$

Hence, the present study was aimed to analyze the microbiological agents that cause chronic suppurative otitis media and their antibiotic resistance patterns among the patients who attended the ENT department of our hospital.

\section{Materials and methods}

The present study was conducted among patients with CSOM who attended Outpatient department of a tertiary care institute for a period of 1year from July 2016 to June 2017. Total number of 100 swabs were obtained and investigated. Patients using topical or systemic antibiotics were excluded from the study. Ear discharge was collected using sterile swab sticks which were labeled and sent to the laboratory for bacteriological and fungal culture studies.

The swabs were placed on MacConkey agar, Blood agar and Chocolate agar and incubated aerobically at $37^{\circ} \mathrm{C}$ for 24 hours. The organisms were identified according to standard microbiological procedures. ${ }^{8}$ All isolated strains were tested for susceptibility to antibiotics on Mueller Hinton Agar using Kirby Bauer disc diffusion method. Results were interpreted using Clinical Laboratory Standards Institute (CLSI) guidelines. ${ }^{9}$

Fungi identified by small amount of material spread over glass slide with inoculating loop in solution of $\mathrm{KOH} \&$ examination done under microscope for hyphae. Rest of material cultured on SDA medium with chloramphenicol without cycloheximide (actidione). The culture tube kept at $220 \mathrm{C}$ for $2-4$ weeks. Isolate was identified from colony characters, macroscopic and microscopic examination was done to identify fungus. In the case of yeast, germ tube fermentation test was done for identification of Candida Albicans. 


\section{Results}

Total of 100 ear swabs were cultured, of which in 90 swabs growth was observed ,among 90 fungal culture was positive in $28(28 \%)$ while combined bacteria and fungi obtained in $24(24 \%)$ cases and only bacteria in $62(62 \%)$ cases. 10 swabs did not show the growth of any pathogen (Table 1$)$.

Table I Showing growth results in 100 swabs

\begin{tabular}{lll} 
& Number & Percentage \\
\hline Total Swabs & 100 & \\
Only bacterial growth & 62 & $62 \%$ \\
Only fungal growth & 4 & $4 \%$ \\
Bacterial \& fungal growth & 24 & $24 \%$ \\
No growth & 10 & $10 \%$ \\
\hline
\end{tabular}

Pseudomonas aeruginosa was the most common bacteria isolated from the bacterial culture $(n=32 ; 37.21 \%)$ followed by Staphylococcus aureus $(\mathrm{n}=22 ; 27.91 \%)$ and klebsiella $(\mathrm{n}=12 ; 13.95 \%)$ (Table 2$)$.

Table 2 Showing types of bacterial growth

\begin{tabular}{lll}
\hline Bacteria Isolated from Swab Culture & Number & Percentage \\
\hline Pseudomonas aeruginosa & 32 & $37.21 \%$ \\
Staphylococcus aureus & 24 & $27.91 \%$ \\
\hline
\end{tabular}

Table Continued..

\begin{tabular}{lll}
\hline Bacteria Isolated from Swab Culture & Number & Percentage \\
\hline klebsiella pneumoniae & 12 & $13.95 \%$ \\
Proteus & 9 & $10.46 \%$ \\
Esterichia coli & 4 & $4.65 \%$ \\
Streptococcus pneumoniae & 3 & $3.49 \%$ \\
Streptococcus pyogens & 2 & $2.33 \%$ \\
Total & 86 & $100 \%$ \\
\hline
\end{tabular}

Aspergillus was the most common fungi isolated from fungal culture of the swab $(\mathrm{n}=16 ; 57.14 \%)$ followed by Candida species $(12=1 ; 42.86 \%)$ (Table 3$)$

Table 3 Showing types of fungal growth

\begin{tabular}{lll}
\hline Fungus Isolated & Number & Percentage \\
\hline Aspergillus Species & 16 & $57.14 \%$ \\
Aspergillus Fumigatus & 9 & $32.14 \%$ \\
Aspergillus Flavus & 3 & $10.71 \%$ \\
Aspergillus Niger & 4 & $14.29 \%$ \\
Candida Species & 12 & $42.86 \%$ \\
Candida Albicans & 12 & $42.86 \%$ \\
Total & 28 & $100 \%$ \\
\hline
\end{tabular}

Amikacin was found to be most effective against gram negative bacteria including pseudomonas aeruginosa (Table 4).

Table 4 Showing antibiotic sensitivity results

\begin{tabular}{|c|c|c|c|c|c|c|c|}
\hline Organism & Amoxyclav & Ceftazidime & Piperacillin & Erythromycin & Ciprofloxacin & Amikacin & Chloramphenicol \\
\hline $\begin{array}{l}\text { Pseudomonas } \\
\text { aeruginosa [32] }\end{array}$ & - & 17 & 16 & - & 13 & 18 & - \\
\hline Staphylococcus & 11 & 13 & 2 & 12 & 9 & 14 & 7 \\
\hline \multicolumn{8}{|l|}{ Aureus [24] } \\
\hline $\begin{array}{l}\text { Klebsiella } \\
\text { pneumoniae [12] }\end{array}$ & - & 3 & 4 & I & 1 & 7 & 5 \\
\hline Esterichia coli [4] & 2 & 1 & 2 & - & 3 & 4 & I \\
\hline $\begin{array}{l}\text { Streptococcus } \\
\text { pneumoniae [3] }\end{array}$ & 2 & 2 & - & I & 1 & I & 1 \\
\hline $\begin{array}{l}\text { Streptococcus } \\
\text { pyogens [2] }\end{array}$ & 1 & I & - & I & 1 & I & 1 \\
\hline
\end{tabular}

\section{Discussion}

In the microbiological study of CSOM various organisms were isolated. Of the 100 ear swabs cultured ,fungal culture was positive for $28(28 \%)$ swabs , while combined growth of fungi and bacteria obtained from 24(24\%) swabs, only bacteria from 62(62\%)and no culture from 10 swabs. Similar study reported by Sen Gupta et al., ${ }^{10}$ results were $24.8 \%, 13.6 \%, 11.2 \%, 66.4 \%$ and $8.6 \%$ respectively.

In the present study Pseudomonas aeruginosa (37.21\%) was found to be the most common organism followed by Staphylococcus aureus (27.91\%) klebsiella (13.95\%), proteus (10.46\%), Escherichia coli $(4.65 \%)$. Studies conducted by Afolabi \& Vishwanath et al., ${ }^{11,12}$ also concluded that pseudomonas aeruginosa was the commonest isolate followed by staphylococcus aureus. ${ }^{11,12}$ Whereas study of Prakash et al., ${ }^{13}$ showed that staphylococcus aureus was the predominant organism in CSOM.

The most commonly found fungi in CSOM are Aspergillus and Candida species .In our study, fungal etiology was found in 28 cases, out of which $57.14 \%$ were Aspergillus species, followed by Candida (42.86\%). Among Aspergillus species maximum strains isolated was Aspergillus fumigates 9(32.14\%) followed by Aspergillus niger 4(14.29\%). In a study from Nigeria on 569 patients of otitis media, fungi isolated were Aspergillus niger (9.2\%) followed by Candida albicans (5.4\%). ${ }^{14}$ In another study from India, fungal etiology was found in $15 \%$ of cases ,out of which $60 \%$ were Candida species and $40 \%$ were Aspergillus species. ${ }^{15}$

No growth was observed in $10 \%$ ear swabs in the present study. This can be explained in two ways, either can be due to middle ear infection by strict anaerobes or due to viral agents like respiratory syncytial virus, adeno viris and influenza virus.

In the present study Amikacin was found to be effective against all the bacteriological species isolated. Similar to our study findings, Amikacin was found to be most effective drug, in the study by Prakash et al.. ${ }^{13}$ Other studies also observed similar patterns of antibiotic sensitivity. ${ }^{15,16,17}$

In a prospective study on bacteriology of squamous type of chronic otitis media with complications, Pseudomonas and Proteus were the most common organisms isolated in patients with complications. Knowledge about the most common organisms causing chronic 
otitis media with complications can help to prevent the same and the antibiotic sensitivity pattern should guide in appropriate management of CSOM and halt the progression of complication at an early stage. ${ }^{18}$

\section{Conclusion}

Pseudomonas species is the major offending pathogen in CSOM and Amikacin is found to be the most effective antibiotic with low resistance rate. The organisms are increasingly becoming resistant to the common and routine antibiotics like fluoroquinolones and penicillin group drugs. Hence, antibiotic susceptibility tests should guide the management of CSOM.

\section{Conflicts of interest}

Author declares there are no conflicts of interest.

\section{Acknowledgments}

None.

\section{Funding}

None.

\section{References}

1. Quinton G. Pathology and clinical course of the inflammatory diseases of the middle ear. In: Aina JG, et al. (Eds.), Glasscock-Shambaugh's Surgery of the Ear, ( $6^{\text {th }}$ edn), People's Medical Publishing House, USA. 2010. p. 427-428.

2. Healy GB, Rosbe KW. Otitis media and middle ear effusion in snow. In Ballenger JJ (Ed.), Ballenger's otorhinolaryngology head neck surgery. BC Decker inc, Canada. 2003.

3. Loy AHC, Tan AL, Lu PKS. Microbiology of chronic supurative otitis media in Singapore. Singapore Med J. 2002;43(6):296-299.

4. Sweeney G, Piccozi GL, Browning GG. A quantitative study of aerobic and anaerobic bacteria in chronic suppurative otitis media. $J$ Infect. 1982;5(1):47-55.

5. Rossolini GM, Mantengoli E, Docquier JD, et al. Epidemiology of infections caused by multiresistant Gram-negatives: ESBLs, MBLs, panresistant strains. New Microbiol. 2007;30(3):332-339.
6. Menichetti F. Current and emerging serious Gram-positive infections. Clin Microbiol Infect. 2005;11(Suppl 3):22-28.

7. Ghonaim MM, El-Edel RH, Basiony LA, et al. Risk factors and causative organisms of otitis media in children. Ibnosina J Med BS. 3(5):172-181.

8. Forbes BA, Sahm DF, Weissfeld AS. Bailey and Scott's Diagnostic Microbiology. (12th edn), Mosby Inc., St. Louis, Missouri, USA. 2007;93-119.

9. Clinical and Laboratory Standard Institute; Performance standards for antimicrobial susceptibility testing. Pennsylvania, USA. 2007.

10. Sen Gupta RP, Kacker SK. Otomycosis. Indian J Medical sciences. 1978;32:5-7.

11. Afolabi O, Salaudeen A, Ologe F, et al. Pattern of bacterial isolates in the mid-dle ear discharge of patients with chronic suppura-tive otitis media in a tertiary hospital in North cen-tral Nigeria. Afr Health Sci. 2012;12(3):362-368.

12. Vishwanath S, Mukhopadhyay C, Prakash R, et al. Chronic Suppurative Otitis Media: Optimizing Initial Antibiotic Therapy in a Tertiary Care Setup. Indian J Otolaryngol Head Neck Surg. 2012;64(3):285-289.

13. Prakash R, Juyal D, Negi V, et al. Microbiology of chronic suppurative otitis media in a tertiary care setup of Uttarakhand state, India. $N \mathrm{Am} \mathrm{J}$ Med Sci. 2013;5(4):282-287.

14. Osazuvza F, Osazuwa E, Osime C, et al. Etiologic agents of otitis media in Benin city, Nigeria. N Am J Med Sci. 2011;3(2):95-98.

15. Kumar H, Seth S. Bacterial and fungal study of 100 cases of chronic suppurative otitis media. J Clin Diagn Res. 2011;5:1224-1227.

16. Mansoor T, Musani MA, Khalid G, et al. Pseudomonas aeruginosa in chronic suppurative otitis media: Sensitivity spectrum against various antibiotics in Karachi. J Ayub Med Coll Abbottabad. 2009;21(2):120-123.

17. Gulati SK. Investigative profile in patients of chronic suppurative otitis media. Indian J Otol. 1997;3:59-62.

18. Viswanatha B, Durganna S, Ravikumar R, et al. Bacteriology of active squamous type of chronic otitis media with complications. Research in Otolaryngology. 2014;3(2):9-15. 